INFORMASI: Kajian Ilmu Komunikasi-ISSN (p) o126-065o; ISSN (e) 2502-3837

Vol. 48. No. 2 (2018). Pp.243-255. doi: https://doi.org/10.21831/informasi.v48i2.21148

\title{
THE NARRATION OF DIGITAL LITERACY MOVEMENT IN INDONESIA
}

\author{
Mery Yanti \\ mery.yanti@fisip.unsri.ac.id \\ Yusnaini \\ yusnaini@fisip.unsri.ac.id \\ Universitas Sriwijaya
}

\begin{abstract}
This article aims to analyze the digital literacy movement in Indonesia and its determinant using the narrative approach. Empirical research is carried out with qualitative content analysis methods. The primary data of the study came from 255 online news which contained digital literacy keywords that were detected by Google search engines and published in trusted online media. Secondary data collected from publications of government, private, and civil society organizations related to digital literacy. We use an interactive model and Atlas.ti 8 to analyze research data. The results showed that each actor had a variety of views about the definitions and situations that underlie digital literacy problems. The digital literacy movement narrative in Indonesia can be explained using the logic of the problem - solution - results. Problem narratives tend to be based on data from a variety of data sources on the profile and behavior of internet users, the development of e-commerce, digital security and crime, digital radicalism, basic competencies of digital literacy, national competitiveness, and the online mass media industry. Starting from the problem narrative, the actors proposed the same solution, namely strengthening digital literacy of internet users, although they differed in identifying target groups. The goals of this solution are a reduction in digital crime, an increase in the digital economy, knowledge, digital skills, and digital governance, as well as the birth of practices in the use of information and communication technology that refers to three principles, namely: security principle, economic principles, and social-cultural principle. We identified four actors who acted as victims in the digital literacy movement narrative in Indonesia: society as a whole, religious institutions, state institutions, population, economic commodities, and market participants. The criminal's character includes internet users, legal players, government institutions, and politicians. Meanwhile, heroes are all actors acting in the digital literacy movement in Indonesia. Fours factors contributed to digital literacy movement: public participation, commitment and togetherness, shared goals and interests, and a massive, systematic, and synergistic strategy, movement management, and learning process. We discuss the theoretical and practical implications of these findings.
\end{abstract}

Keywords: Digital Competency, Digital Literacy, Internet, Narrative Approach, Social Movement. 


\section{NARASI GERAKAN LITERASI DIGITAL DI INDONESIA}

\section{Abstrak}

Artikel ini bertujuan menganalisis gerakan literasidigital di Indonesia dan determinannya dengan pendekatan naratif. Riset empiris dilaksanakan dengan metode analisis isi kualitatif. Data primer penelitian berasal dari 255 berita online yang mengandung kata kunci "literasi digital" yang di deteksi mesin pencari Google dan dipublikasikan di media online terpercaya. Data sekunder dikumpulkan dari publikasi organisasi pemerintah, swasta, dan/atau masyarakat sipil yang berhubungan dengan literasi digital. Analisis data penelitian menggunakan model interaktif dengan bantuan software Atlas.ti 8. Hasil penelitian menunjukkan setiap aktor memiliki keragaman pandangan tentang definisi dan situasi yang melatari masalah literasi digital. Alur cerita gerakan literasi digital di Indonesia bisa dijelaskan menggunakan logika masalah - solusi - hasil. Narasi masalah cenderung berbasis data dari beragam sumber data tentang profil dan perilaku pengguna internet, perkembangan e-commerce, keamanan dan kriminalitas digital, radikalisme digital, kompetensi dasar literasi digital, daya saing bangsa, dan industri media massa daring. Bertolak dari narasi masalah, para aktor mengusulkan solusi yang sama, yakni penguatan literasi digital pengguna internet, meski berbeda dalam identifikasi kelompok sasaran. Hasil akhir solusi ini adalah berkurangnya kriminalitas digital, meningkatnya perekonomian digital, pengetahuan, keterampilan digital, dan digital governance, serta melahirkan praktik-praktik penggunaan teknologi informasi dan komunikasi yang mengacu ke tiga prinsip, yakni: prinsip keamanan, prinsip ekonomi, dan prinsip sosio-kultural. Peneliti mengidentifikasi empat aktor yang berperan sebagai korban dalam narasi gerakan literasi digital di Indonesia, yakni: masyarakat secara keseluruhan, institusi agama, institusi negara, populasi penduduk, komoditas ekonomi, dan para pelaku pasar. Para penjahatnya meliputi pengguna internet, para pelaku pasar berbadan hukum, institusi pemerintah, dan oknum para politisi. Sedangkan, pahlawannya adalah semua aktor yang bertindak nyata dalam gerakan literasi digital di Indonesia. gerakan literasi digital dipengaruhi empat faktor yakni: partisipasi publik, komitmen dan kebersamaan, tujuan dan kepentingan bersama, dan strategi yang masif, sistematis, dan sinergis, manajemen gerakan, dan proses pembelajaran. Peneliti mendiskusikan implikasi teoretis dan praktis temuan ini.

Kata Kunci: Gerakan Sosial, Internet, Kompetensi Digital, Literasi Digital, Pendekatan Naratif

\section{PENDAHULUAN}

Menurut hasil survei Asosiasi Penyelenggara Jasa Internet Indonesia (APJII), dari total penduduk Indonesia yang mencapai 256,2 juta orang, pengguna internet mencapai 132,7 juta. Jumlah ini tersebar di Jawa (65 persen), Sumatera (15,7 persen), Sulawesi $(6,3$ persen), Kalimantan (5,8 persen), Bali dan Nusa (4,7 persen), dan Papua (2,5 persen). Pengguna internet laki-laki mencapai 51,8 persen dan netizens perempuan mencapai 48,2 persen (APJII, 2016). Perkembangan ini cukup menggembirakan sekaligus mengkhawatirkan. Dianggap menggembirakan karena sebagian warga negara Republik Indonesia sudah menikmati kecanggihan teknologi informasi dan komunikasi beserta manfaat turunnya. Hal ini selaras dengan riset-riset sebelumnya yang menunjukkan bagaimana internet memicu lahirnya e-learning (Hidayat, 2017: 17-36; Knox, 2014: 164-177), e-commerce (Ardiansyah, Yunizar, \& Harsanto, 2016: 243-254; Astuti \& Nasution, 2014: 69-88; Santosa, 2001: 126141), e-procurement (Aprizal \& Purba, 2013: 15-28; Harjito, Achyani, \& Payamta, 2015: 6182), e-voting (Hilbert, 2009: 87-110; Kahani, 
2006: 113-125), dan e-health (Coleman, 2014: 1-7; Wentink, Prieto, de Kloet, Vliet Vlieland, \& Meesters, 2017: 1-6).

Tetapi, penetrasi internet yang cukup tinggi juga diiringi dengan lahirnya beragam persoalan sosial baru, misalnya berita hoax, bullying, pornografi, penyebar kebencian, perjudian daring, transaksi seks daring, pencurian informasi, dan sebagainya. Beberapa riset sebelumnya sudah mengidentifikasi implikasi negatif internet dengan istilah patologi informasi (Bawden \& Robinson, 2009, 180-191), ketidakadilan digital (Robinson et al., 2015, 569-582), masalah sosial global (Drori, 2014: 433-450). Begitu besarnya dampak beragam persoalan ini bagi kehidupan bangsa Indonesia, mendorong Pemerintah Republik Indonesia mengeluarkan Undang - Undang Nomor 11 Tahun 2008 tentang Informasi dan Transaksi Elektronik. Yang terbaru, sebagai turunan dari undang-undang ini, adalah dibentuknya Badan Siber dan Sandi Nasional (BSSN) melalui Peraturan Presiden Republik Indonesia Nomor 53 Tahun 2017 dengan tugas utama melaksanakan keamanan siber secara efektif dan efisien dengan memanfaatkan, mengembangkan, mengonsolidasikan semua unsur yang terkait dengan keamanan siber.

Pemerintah pusat sebetulnya sudah memiliki program untuk meningkatkan literasi digital (LD) para pengguna internet, yakni program Internet Sehat dan program \#SiBerkreasi. Kedua program ini difasilitasi pemerintah, melibatkan banyak pihak dari beragam kalangan, dan bukan inisiatif dari pengguna internet. Tetapi, dua program ini tetap saja belum mampu mengelola kompleksitas persoalan LD di Tanah Air. Intinya, pemerintah tetap membutuhkan partisipasi dari para pengguna internet untuk merespons persoalan LD. Tetapi, pemerintah sebetulnya membutuhkan informasi awal seperti apa dan bagaimana sesungguhnya tindakan-tindakan nyata yang dilakukan para pengguna internet untuk meningkatkan LD sesama mereka. Jika pengetahuan ini bisa dipetakan, maka pemerintah bisa memosisikan diri secara tepat dalam mendukung gerakan LD yang dikelola para pengguna internet dengan prinsip kerelawanan. Ide penelitian ini lahir dari semangat dan logika berpikir pragmatis seperti ini.

Di samping itu, dari sudut pandang akademik, penelitian ini menjadi penting dilaksanakan karena dua hal: pertama, kajian LD lebih banyak dipotret dari sudut pandang e-learning. Kedua, penelusuran artikel ilmiah selama lima tahun terakhir (2014-2018) di SCOPUS dengan kata kunci "digital literacy" AND "social movement" hanya menampilkan 1 (satu) artikel, yakni artikel Emejulu \& McGregor (2016, 1-17). Di Indonesia, baru ada 2 (dua) artikel yang menjelaskan gerakan LD (lihat, Jordana \& Suwarto, 2017, 167-180; Kurnia \& Astuti, 2017, 167-180). Hal ini menunjukkan minimnya perhatian para ilmuwan yang melihat fenomena LD dari sudut pandang teori gerakan sosial. Pada titik ini, penelitian ini diharapkan dapat berkontribusi signifikan dalam perdebatan ilmiah tentang LD.

Ada beberapa penelitian yang telah menggunakan pendekatan naratif untuk menjelaskan gerakan sosial. Studi Nielsen (2009, 448-468) di India menemukan beragam makna yang diberikan aktor terhadap gerakan sosial yang mereka ikuti. Riset Clark (2016, 788-804) menelaah gerakan sosial online para feminis di Twitter dengan hashtag \#WhyIStayed. Di Cina, Huang (2016, 788-804) meneliti gerakan petisi online yang diinisiasi beberapa warga negara. Meskipun sama-sama menggunakan pendekatan naratif, riset ini berbeda dengan studi Nielsen (2009, 448-468), Clark (2016, 788-804), dan Huang (2016, 788-804) karena peneliti menggunakan pendekatan Narrative Policy Framework (McBeth, Jones, \& Shanahan, 2014). Selain itu, objek empiris ketiga riset ini fokus ke gerakan sosial daring, sedangkan ketiga penelitian sebelumnya fokus ke gerakan LD yang terjadi di level dunia nyata.

Secara teoretis, terminologi literasi memiliki empat makna. Pertama, kemampuan membaca dan menulis yang menjadi prasyarat bagi seseorang terlibat 
interaksi sosial. Kedua, kemampuan membaca, menulis, dan berhitung. Ketiga, merujuk ke kualitas seseorang yang intelek dan berpendidikan sehingga mampu berpartisipasi secara penuh dalam aktivitas kemasyarakatan, baik di sektor sosial, ekonomi, politik, dan budaya. Keempat, literasi merupakan karakteristik kelompok sosial atau budaya tertentu (Stokes, 2008, 6o8-616).

Literasi melekat secara mendalam kehidupan sosial (Kalman, 2008, 523-538). Ketika lanskap kehidupan sosial berubah, maka literasi juga berubah. Hari ini, kehidupan manusia dikonseptualisasikan secara berbeda oleh para ilmuwan, mulai dari information society (Webster, 2010, 443458)this Student Edition of the successful Handbook of New Media has been abridged to showcase the best of the hardback edition, knowledge society (Krohn, 2001, 8139-8143), post-industrial society (Crouch, 2001, 7347-7351). Di era information society, knowledge society, atau post-industrial society, kemampuan membaca, menulis, dan berhitung yang dimiliki setiap individu tidak lagi memadai dijadikan prasyarat partisipasi dalam beragam sektor kehidupan sosial. Inovasi teknologi komputer dan komunikasi meningkatkan kemampuan manusia dalam memproduksi, mendistribusikan, dan mengonsumsi informasi secara masif. Informasi tidak lagi dipahami hanya sebatas huruf dan angka, tetapi meliputi gambar, suara, dan audio visual yang diproduksi, didistribusikan, dan dikonsumsi melalui beragam media.

Di era masyarakat informasi, setiap individu berhadapan dengan proses dan media komunikasi yang multimodality (Cope \& Kalantzis, 2009, 164-195) dan karenanya membutuhkan kompetensi multiple literacies (Kellner, 2001, 67-81) yang berisi technology literacy (Erstad, 2010, 34-41; Gamire \& Pearson, 2006), media literacy (Sterling, 2009, 884-887), dan information literacy (Godwin, 2006, 268-287; Pinto, Pulgarín, \& Escalona, 2014, p. 2.311-2.329). Penemuan teknologi internet memungkinkan terjadinya konvergensi ketiga literasi ini. Karena internet hanya mengenal data binary atau data digital ( 1 atau o), maka ketiga literasi ini sering dianggap sebagai elemen pokok LD (Koltay, 2011, 211-221; Martin \& Grudziecki, 2006, 1-19).

Tetapi, beberapa ilmuwan melihat LD dengan cara yang berbeda. Reynolds (2016, 735-762) misalnya, menganggap LD berisi enam elemen pokok yang saling berhubungan satu sama lain, yakni: create (membuat), manage (mengelola), publish (mempublikasikan), socialize (mensosialisasikan), research (mencari), surf (berselancar). Gruszczynska \& Pountney (2013, 25-36) melihat LD lebih ke persoalan akses, keterampilan, praktik, dan konteks sosio-kultural. Sedangkan Bulger, Mayer, \& Metzger (2014, 1567-1583) melihat LD sebagai kemampuan membaca dan menulis dengan menggunakan sumber daya daring, menyeleksi sumber daya daring, menyintesiskan informasi menjadi pesan yang koheren, dan mengomunikasikan pesan ke penerima pesan. Sudut pandang LD sebagai keterampilan (skill) juga diungkapkan Helsper \& Eynon (2013, 696713) yang membagi digital skill ke dalam empat kategori, yakni: critical, social, creative dan technical skills. Bagi Ilomäki, Paavola, Lakkala, \& Kantosalo (2016, 655679), digital skill hanya salah satu komponen konsep digital competence. Jika LD dijelaskan dengan konsep digital competence, maka LD juga meliputi: (a) kemampuan menggunakan teknologi digital secara bermakna dalam kehidupan sehari-hari; (b) kemampuan mengevaluasi teknologi digital secara kritis; dan (c) motivasi berpartisipasi dalam budaya digital.

Sementara itu, konsep gerakan sosial merupakan abstraksi tingkat tinggi fenomena sosio-kultural yang kompleks dan mengandung elemen identitas kolektif, kohesi, kontinuitas, jejaring kelompok dan individu, dan tujuan perubahan sosial, organisasi dan struktur politik, emosi, budaya, pengaruh media, dan framing (Refle, 2016, 244-245; Travaglino, 2014, 1-14). Gerakan sosial adalah salah satu bentuk tindakan kolektif yang ada di masyarakat. 
Ia bukan tindakan individu, tetapi tindakan beragam individu. Sekumpulan individu ini bertindak kolektif karena memiliki tujuan, kepentingan, nilai, atau imagined solidarity (Bayat, 2005, 891-908), social consciousness (McNall, 1986, 3-28), atau belief system (Mueller \& Judd, 1981, 182187) yang sama. Ide ini tentu saja bertolak belakang dengan argumentasi Olson (1971, p. 2) yang menyatakan bahwa setiap individu dalam kolektivitas tertentu tidak akan pernah bertindak untuk mencapai tujuan kolektif, tetapi hanya akan bertindak untuk memenuhi kepentingan pribadinya.

Menurut Buechler (1993, 217-235), ada beberapa teori yang berkembang di kalangan sosiolog untuk menjelaskan fenomena gerakan sosial. Yang pertama adalah teori resource mobilization (RM) yang melihat gerakan sosial sebagai sesuatu yang terstruktur dan memiliki pola-pola tertentu sehingga bisa dianalisis dengan konsep dinamika organisasi. Gerakan sosial akan efektif ketika memiliki akses ke sumber daya dan di topang sumber manusia yang bermotivasi tinggi. Pertemuan dua hal ini akan memicu proses mobilisasi yang mampu melahirkan identitas kolektif.

Yang kedua, lanjut Buechler (1993, 217235), adalah teori perubahan sosial yang bisa kelompokkan menjadi dua jenis, yakni political-centered dan cultural-centered. Teori political-centered melihat totalitas masyarakat dengan konsep kapitalisme lanjut. Dalam masyarakat seperti ini, kekuasaan bersifat tunggal, sistemis, dan terpusat. Gerakan sosial di lihat sebagai varian baru gerakan kelas dan akan bersifat progresif jika beraliansi dengan gerakan kelas. Gerakan sosial adalah gerakan politik dan bersifat radikal. Sebaliknya, gerakan budaya bersifat apolitis. Analisis gerakan sosial fokus ke lokasi dan situasi kontradiktif, kelas menengah, dan kelas-kelas sosial baru. Sementara itu, kelompok teori culturaloriented melihat gerakan sosial sebagai ekspresi simbolik, berpotensi menggantikan perjuangan kelas, dan bersifat radikal. Sebaliknya, gerakan politik dianggap tidak radikal karena dapat dikooptasi pihak-pihak tertentu. Analisis gerakan sosial fokus ke isu, ideologi, dan konstituen non-kelas.

\section{METODE}

Penelitian ini menggunakan pendekatan analisis isi kualitatif (Elo et al., 2014; Morgan, 1993) yang dikombinasikan dengan pendekatan narrative policy framework (McBeth et al., 2014) untuk menganalisis narasi gerakan LD di Indonesia. Konsekuensinya, empat elemen inti dalam analisis narrative policy framework akan dijadikan sebagai fokus penelitian, yakni: latar (setting), aktor (character), alur cerita (plot), solusi (moral) (McBeth et al., 2014).

Data primer penelitian ini berasal dari web berbentuk news (berita) yang mengandung kata kunci frase "literasi digital". Pada 9 Januari 2018, Google ${ }^{\odot}$ menampilkan 350 web yang mengandung kata kunci ini. Halaman web ini dibuka satu per satu menggunakan aplikasi Safari ${ }^{\odot}$ versi 11.1.1 (13605.2.8) untuk kemudian disimpan dalam bentuk portable document format (PDF). Karena proses duplikasi berita, peneliti hanya mendapatkan 255 dokumen yang diikutsertakan dalam proses analisis data selanjutnya yang menggunakan aplikasi ATLAS.ti ${ }^{\odot}$ versi 8.2.4 (559). Tahapan analisis data mengikuti tiga tahapan. Tahap pertama analisis data adalah pengkodean data. Pada fase ini, peneliti membaca narasi teks dengan tujuan mengkode data ke dalam code. Proses pengkodean ini mengacu ke fokus penelitian dan menghasilkan kategori-kategori tertentu yang siap dianalisis lebih jauh. Di tahap kedua, peneliti akan menampilkan data yang sudah diolah dengan bantuan ATLAS.ti ${ }^{\odot}$. Di tahap ketiga, peneliti akan menunjukkan dan mendiskusikan temuan penelitian. Satuan analisis penelitian ini adalah lembaga, organisasi, atau institusi. Meskipun yang bertindak di lapangan adalah individu, tetapi tindakan individu dianggap mencerminkan perilaku lembaga, organisasi, atau institusi. Sedangkan data sekunder dikumpulkan dari publikasi organisasi pemerintah, swasta, dan/atau masyarakat sipil yang berhubungan dengan LD. Bentuk data sekunder bisa 
berupa jurnal ilmiah, laporan atau berita resmi lembaga.

\section{HASIL DAN PEMBAHASAN}

\section{Struktur narasi gerakan literasi digital}

\section{Latar}

Latar adalah situasi kehidupan sosial manusia yang melahirkan masalah LD. Setiap aktor, karena perbedaan afiliasi organisasi, sudut pandang, dan kepentingan jangka panjang, memiliki keragaman pandangan tentang situasi hari ini yang melahirkan masalah LD. Hasil coding data primer dengan ATLAS.ti ${ }^{\odot}$ versi 8 menunjukkan bahwa aktor pemerintah cenderung melihat kesenjangan digital, radikalisme, kriminalitas digital, konten negatif, dan rendahnya LD sebagai situasi yang mendorong perlunya gerakan LD. Sementara itu, aktor korporasi swasta mengidentifikasi kesenjangan edukasi LD, rendahnya kewirausahaan digital, rendahnya pembayaran digital, rendahnya transaksi keuangan digital, kesenjangan digital anak, dan kesenjangan teknologi digital sebagai masalah yang harus diintervensi dengan LD. Berbeda dengan kedua aktor ini, para pelaku masyarakat sipil hanya mengidentifikasi empat masalah yang melahirkan gerakan digital yakni: pergeseran minat baca ke informasi digital, rendahnya e-commerce, kesenjangan digital, maraknya konten negatif, dan rendahnya LD penduduk Indonesia.

Terlepas dari definisi setiap istilah yang menggambarkan situasi masalah internet di Indonesia yang berhasil di identifikasi para aktor gerakan LD, setiap istilah ini tidak berdiri sendiri, tetapi terkoneksi satu dengan yang lainnya. Koneksi ini bisa bersifat kausalitas (misalnya, maraknya konten negatif disebabkan karena rendahnya LD), asosiatif (misalnya, radikalisme agama berasosiasi dengan rendahnya LD), dan indikatif (misalnya, rendahnya transaksi pembayaran digital merupakan indikator perkembangan e-commerce). Jika disederhanakan, maka situasi masalah internet di Indonesia direpresentasikan dua istilah, yakni: adanya kesenjangan digital dan rendahnya LD yang saling berasosiasi. Jika LD adalah arus utama, maka terdapat tiga arus kecil yang mengalir di sepanjang arus utama ini, yakni: e-learning, e-commerce, dan e-security, yang memiliki alur cerita sendiri.

\section{Alur cerita}

Dalam konteks gerakan LD, meski setiap aktor memiliki cara dan narasi yang berbeda tatkala mengonstruksi narasi gerakan LD, tetapi alur cerita mereka memiliki kesamaan, yakni: masalah, solusi, dan hasil. Alur cerita ini mengikuti cara berpikir sistem yang terdiri atas komponen input, proses, output, dan umpan balik.

Awal cerita aktor selalu dimulai dengan data ilmiah, baik yang berhubungan dengan tingkat penetrasi TIK maupun perilaku pengguna internet di Indonesia. Sumber datanya berasal dari 18 (delapan belas) lembaga, baik institusi pemerintah, semipemerintah, universitas, asosiasi korporasi, korporasi bisnis, organisasi masyarakat sipil, maupun organisasi internasional. Pengguna data ini bisa berasal dari institusi pemerintah, masyarakat sipil, korporasi, atau individu. Substansi data yang digunakan pengguna data meliputi beberapa tema, yakni: profil dan perilaku pengguna internet, perkembangan e-commerce, keamanan dan kriminalitas digital, radikalisme digital, kompetensi literasi dasar, daya saing bangsa, dan industri media massa daring. Data profil dan perilaku pengguna internet yang diproduksi APJII paling banyak digunakan para pemangku kepentingan LD di Indonesia. Inti data APJII adalah tingginya penetrasi internet di Indonesia yang dipersepsikan beragam pemangku kepentingan melahirkan banyak masalah di tengah masyarakat. Bertolak dari persepsi tentang masalah, para aktor kemudian menawarkan solusi untuk menyelesaikan masalah.

\section{Solusi}

Solusi adalah pesan moral para aktor dalam narasi LD. Semua aktor sepakat bahwa meningkatkan kualitas LD adalah kata kunci untuk mengelola beragam persoalan yang 
muncul akibat penetrasi teknologi informasi dan komunikasi di Tanah Air. Perbedaannya hanya terletak pada istilah kelompok sasaran. Ada yang menggunakan istilah pengguna internet, warga negara, komunitas, guru dan pelajar, polisi, masyarakat, anakanak dan generasi muda, penduduk, pelaku usaha UMKM. Perbedaan ini menunjukkan keragaman fokus para aktor dalam mengelola persoalan LD di Indonesia.

Perbedaan juga terlihat dalam aspek hasil yang diharapkan. Peneliti mengidentifikasi empat tema hasil yang menjadi perhatian para pemangku kepentingan LD di Indonesia, yakni: kriminalitas digital (misalnya, radikalisme, terorisme, ujaran kebencian, berita palsu, perundungan, pornografi), perekonomian digital (misalnya, keuangan mikro digital, pembayaran digital, e-commerce, cashless society), pengetahuan dan keterampilan digital (misalnya, teknik mengonsumsi, produksi, dan distribusi informasi digital), dan digital governance (misalnya, regulasi, penegakkan hukum, dukungan kebijakan). Terkait dengan empat tema ini, tema pengetahuan dan keterampilan digital menjadi tema dominan yang disoroti para pemangku kepentingan.

\section{Karakter}

Menurut McBeth, Jones, \& Shanahan (2014), setiap narasi kebijakan minimal mengandung tiga karakter, yakni korban (tokoh yang disakiti), penjahat (tokoh yang menyakiti), dan pahlawan (tokoh yang membantu korban atau membasmi penjahat). Dari hasil coding, kami menemukan empat kategori korban penetrasi teknologi informasi dan komunikasi berbasis internet yang dipersepsikan para pemangku kepentingan, yakni: masyarakat secara keseluruhan, institusi agama, institusi negara, populasi penduduk (generasi muda dan anak-anak), komoditas ekonomi (buku cetak dan aplikasi media sosial), dan para pelaku pasar (pengusaha toko buku konvensional dan perusahaan pengembang aplikasi media sosial).
Semua aktor yang disebutkan di atas, baik dari unsur pemerintah (Badan Nasional Penanggulangan Terorisme, Kantor Staf Presiden, Kementerian Informasi dan Komunikasi, Kementerian Pendidikan dan Kebudayaan, dan Kepolisian Republik Indonesia), korporasi (Bank Negara Indonesia, Indosat Ooredoo, PT. Amartha Mikro Fintek, Telkomsel, Tokopedia), dan masyarakat sipil (Siberkreasi, Aliansi Jurnalis Independen, Asosiasi e-Commerce Indonesia, ICT Watch, Jaringan Penggiat Literasi Digital, Majelis Ulama Indonesia, Muhammadiyah, Nahdhatul Ulama, Yayasan Cinta Anak Bangsa, dan Yayasan Taman Baca Inovator), memiliki karakter sebagai pahlawan karena melakukan tindakan nyata untuk menyelamatkan korban penetrasi teknologi informasi dan komunikasi digital.

Predikat kepahlawanan yang dimiliki seluruh aktor ini tidak terlepas dari strategi KOMINFO yang berusaha merangkul seluruh elemen bangsa (misalnya melalui program Siberkreasi dan Mudamudigital) untuk membersihkan udara digital di Tanah Air dari ujaran kebencian, pornografi, berita palsu, perundungan, radikalisme, dan terorisme melalui beragam aktivitas penguatan LD pengguna internet. Meski KOMINFO memiliki sumber daya lebih banyak dibandingkan dengan aktor lainya, tetapi mereka tetap kewalahan untuk mengatasi masifnya penyebaran konten negatif di internet. Sebab, ujung tombak penyebaran konten negatif ada di ujung jari para pengguna internet yang setiap saat bisa memproduksi, mendistribusikan, dan mengonsumsi ribuan informasi dari internet dan media sosial.

\section{Determinan gerakan literasi digital}

Untuk mengidentifikasi determinan gerakan LD, peneliti meng-coding seluruh pernyataan informan yang secara implisit mengandung logika sebab-akibat ke dalam kategori tertentu. Dalam setiap pernyataan ini, gerakan LD diposisikan sebagai variabel bebas (variabel akibat), sedangkan variabel terikat (variabel sebab) adalah substansi pernyataan informan. Di tahap pertama atau 
populer disebut dengan open coding, peneliti mendapatkan beberapa kategori yang sama dan berbeda. Kategori/konsep yang sama dijadikan satu kategori, sedangkan kategori yang berbeda tetap dibiarkan berbeda. Hasil penyederhanaan ini menghasilkan tiga belas kategori. Peneliti menelaah lebih jauh hubungan antar kategori dengan mengacu ke konteks awal kategori/konsep di data penelitian. Pada tahap ini, peneliti berusaha melihat: (a) apakah hubungan antar kategori bersifat kausalitas/sebab-akibat (jika X maka Y); (a) apakah hubungan antar kategori bersifat non-kausalitas karena, misalnya, kategori tertentu merupakan atribut dari kategori lainnya.

Proses analisis ini menghasilkan temuan bahwa gerakan LD dilahirkan cyber governance. Secara sederhana, konsep cyber governance dapat dimaknai sebagai interaksi beragam aktor (pemerintah, para pelaku pasar, dan masyarakat sipil) dalam mengelola dunia digital di Indonesia. Dalam cyber governance, meski aktor pemerintah bukan aktor tunggal, tetapi ia memiliki posisi strategis karena institusi pemerintah yang memiliki legitimasi politik untuk menjalankan peran-peran sebagai regulator. Dalam beberapa kasus, seperti ditunjukkan kasus pemblokiran, institusi pemerintah bisa bersifat koersif dengan alasan melindungi kepentingan publik yang lebih luas.

Di Indonesia, institusi pemerintah ini direpresentasikan oleh Kementerian Informasi dan Komunikasi Republik Indonesia (KOMINFO). Realitas empiris dunia digital di Tanah Air yang dipenuhi konten negatif mendorong KOMINFO untuk memfasilitasi terbentuknya gerakan LD yang bersifat dari, oleh, dan untuk masyarakat, serta fokus di sektor hulu, kecuali infrastruktur fisik (misalnya, proyek Palapa Ring), pembuatan regulasi dan kebijakan (misalnya, undang undang perlindungan data pribadi yang saat ini masih di bahas pemerintah dengan DPR RI), pengawasan (misalnya, pemantauan konten negatif di internet melalui mesin sensor), dan pembangunan ekosistem digital (misalnya, ekosistem e-commerce, finance technology, e-learning, e-health) yang tetap dimotori institusi pemerintah bekerja sama dengan beragam pihak.

Gerakan LD yang diinisiasi KOMINFO ini akan meningkatkan pengetahuan, keterampilan, dan kesadaran individu tatkala memanfaatkan teknologi informasi dan komunikasi dalam kehidupan sehari-hari yang lebih aman, beradab, berdaya, beretika, bermakna, bermanfaat, bermartabat, bijak, cerdas, demokratis, kritis, positif, produktif, dan sehat. Gerakan ini diharapkan dapat melahirkan kurikulum digital yang dapat dijadikan pedoman bagi proses transfer nilai dan pengetahuan ilmiah tentang dunia digital ke beragam elemen penduduk Indonesia di pelbagai jenjang dan tipe pendidikan.

Meski difasilitasi KOMINFO, misalnya program Siberkreasi dan program Mudamudigital, pihak pemerintah berupaya meminimalkan pendekatan hierarki dan memaksimalkan pendekatan kerelawanan untuk mengelola gerakan LD di Tanah Air. Kata kunci keberhasilan gerakan LD berbasis kerelawanan, seperti diungkapkan banyak informan penelitian, terletak pada tema kolaborasi para pemangku kepentingan. Data lapangan mengungkapkan bahwa kolaborasi banyak pihak dalam konteks gerakan LD memiliki beberapa atribut yang saling berhubungan satu sama lain, yakni: (a) partisipasi publik; (b) komitmen dan kebersamaan; (c) tujuan dan kepentingan bersama; (d) strategi yang masif, sistematis, dan sinergis; (d) manajemen gerakan; dan (e) proses pembelajaran.

Jika dihubungkan dengan teori gerakan sosial, gerakan LD di Indonesia sudah layak disebut sebagai gerakan sosial karena memiliki beberapa elemen kunci dalam konsepsi teoretis gerakan sosial yang dikemukakan para ilmuwan, yakni: jejaring kelompok dan individu, tujuan perubahan sosial, budaya, framing, organisasi dan struktur politik (Refle, 2016, 244-245; Travaglino, 2014, 1-14), dan kesadaran sosial (McNall, 1986, 3-28). Selain itu, gerakan LD di Indonesia lebih berorientasi kultural karena berusaha mengintervensi proses produksi, konsumsi, dan distribusi informasi digital yang sarat dengan ekspresi 
simbolik (misalnya, melalui meme digital), klaim identitas (misalnya, pelaku teror, LGBT, kelompok radikal, tentara digital), pertarungan wacana (misalnya, perang tagar antara kelompok \#2019GantiPresiden dengan kelompok \#Jokowi2Periode dan \#2019TetapJokowi), dan tekanan konformitas (misalnya, penggunaan TIK harus memperhatikan nilai-nilai Ketimuran yang dimiliki bangsa Indonesia).

Sementara itu, terkait dengan teori LD, para pelaku gerakan LD di Indonesia sepakat bahwa penetrasi TIK di Tanah Air telah melahirkan proses komunikasi yang multimodal dan membutuhkan kompetensi multi literasi, baik literasi teknologi, literasi media, atau literasi informasi (Cope \& Kalantzis, 2009; Erstad, 2010; Gamire \& Pearson, 2006; Godwin, 2006; Kellner, 2001; Pinto et al., 2014). Berbeda dengan para ilmuwan yang hanya melihat LD hanya sebagai akses, pengetahuan, keterampilan, dan kompetensi mengelola sumber daya digital (Bulger et al., 2014; Gruszczynska \& Pountney, 2013; Helsper \& Eynon, 2013; Ilomäki et al., 2016; Reynolds, 2016), gerakan LD di Indonesia menekankan pentingnya penggunaan teknologi informasi dan komunikasi berbasis nilai yang direpresentasikan tiga prinsip, yakni: prinsip keamanan, prinsip ekonomi, dan prinsip sosio-kultural.

Berbeda dengan riset Nielsen (2009, 448-468) yang mengelompokkan narasi berdasarkan tipe naratornya, peneliti mengelompokkan narasi berdasarkan jenis elemen narasi. Tetapi, hasil penelitian ini menguatkan temuan Nielsen (2009, 448468) perihal narasi yang tumpang tindih, meski penelitian ini tidak menemukan ketegangan dan proses negosiasi yang disebabkan oleh narasi yang tumpang tindih. Sebaliknya, narasi yang tumpang tindih ini semakin memfasilitasi beragam aktor untuk berkolaborasi. Terakhir, gerakan LD di Indonesia tidak hanya terjadi di dunia daring, tetapi juga dunia nyata. Riset ini sebetulnya lebih fokus ke aktivitas gerakan di dunia nyata dan kurang memberikan perhatian ke dunia daring. Oleh karena itu, peneliti tidak bisa memberikan komentar banyak terhadap hasil penelitian Clark (2016, 788-804) dan Huang (2016, 788-804) yang memfokuskan diri ke gerakan sosial di dunia daring.

\section{SIMPULAN}

Penelitian ini bertujuan untuk menganalisis gerakan LD di Indonesia dan determinannya dengan pendekatan naratif. Hasil penelitian menunjukkan setiap aktor memiliki keragaman pandangan tentang latar (situasi kehidupan sosial) yang melahirkan masalah dan definisi masalah LD. Jika disederhanakan, maka situasi masalah internet di Indonesia direpresentasikan dua istilah, yakni: adanya kesenjangan digital dan rendahnya $\mathrm{LD}$ yang saling berasosiasi. Jika LD adalah arus utama, maka terdapat tiga arus kecil yang mengalir di sepanjang arus utama ini, yakni: e-learning, e-commerce, dan $e$-security, yang memiliki alur cerita sendiri.

Alur cerita LD di Indonesia bisa mengikuti logika masalah - solusi - hasil. Narasi masalah yang dikonstruksi para aktor cenderung berbasis data dari beragam sumber data tentang profil dan perilaku pengguna internet (rasa percaya terhadap data, penggunaan media sosial), perkembangan e-commerce, keamanan dan kriminalitas digital, radikalisme digital, kompetensi literasi dasar, daya saing bangsa, dan industri media massa daring. Bertolak dari narasi masalah, para aktor mengusulkan solusi yang sama, yakni penguatan $\mathrm{LD}$, meski berbeda dalam identifikasi kelompok sasaran. Hasil akhir solusi ini adalah berkurangnya kriminalitas digital, meningkatnya perekonomian digital, pengetahuan, keterampilan digital, dan digital governance, serta melahirkan praktikpraktik penggunaan teknologi informasi dan komunikasi yang mengacu ke tiga prinsip, yakni: prinsip keamanan (sehat dan aman), prinsip ekonomi (berdaya, bermanfaat, produktif), dan prinsip sosio-kultural (beradab, beretika, bermakna, bermartabat, bijak, cerdas, demokratis, kritis, positif). Secara umum, ada logika kausalitas yang terkandung dalam alur cerita LD di Indonesia yang dibangun para aktor. 
Peneliti mengidentifikasi empat aktor yang berpredikat sebagai korban dalam narasi LD di Indonesia, yakni: masyarakat secara keseluruhan, institusi agama, institusi negara, populasi penduduk, komoditas ekonomi, dan para pelaku pasar. Para penjahatnya meliputi pengguna internet (baik perorangan maupun kelompok terorganisir dengan motif non-ekonomi), para pelaku pasar berbadan hukum (para pengembang aplikasi berbasis Android), institusi pemerintah, dan oknum para politisi. Sedangkan, pahlawannya adalah semua aktor (pemerintah, korporasi bisnis, dan masyarakat sipil) yang bertindak nyata (perorangan atau kolaboratif) untuk menanggulangi persoalan LD di Indonesia. Karena gerakan LD bersifat kolaboratif, maka ada empat determinan yang mempengaruhi proses ini, yakni: partisipasi publik, komitmen dan kebersamaan, tujuan dan kepentingan bersama, dan strategi yang masif, sistematis, dan sinergis, manajemen gerakan, serta proses pembelajaran.

Terkait dengan upaya penguatan LD pengguna internet di Indonesia, penelitian ini merekomendasikan agar tiga prinsip (keamanan, ekonomi, dan sosio-kultural) yang dihasilkan penelitian ini dapat diadopsi para pemangku kepentingan sebagai salah satu isi materi penguatan LD pengguna internet di Indonesia. Selain itu, meski gerakan LD di Indonesia terjadi di dunia nyata dan dunia daring, tetapi peneliti hanya memfokuskan diri ke aktivitas gerakan LD di dunia nyata, maka ke depan, perlu ada penelitian khusus untuk menganalisis narasi gerakan LD di dunia daring. Fenomena kolaborasi aktor dalam gerakan LD juga dapat ditelaah lebih jauh dengan perspektif teoretis berbasis jejaring, misalnya social network analysis (Scott, 1988; Wasserman \& Faust, 1994), policy network (Blom-Hansen, 1997; Dowding, 1995), atau collaborative management (Agranoff, 2006; Kapucu \& Demiroz, 2011), sehingga pengetahuan ilmiah tentang gerakan LD semakin utuh dan membantu banyak pihak untuk menguatkan LD pengguna internet di Indonesia.
Agranoff, R. (2006). Inside Collaborative Networks: Ten Lessons for Public Managers. Public Administration Review, 66(s1), 56-65. https://doi. org/10.1111/j.1540-6210.2006.00666.X

Aprizal, A., \& Purba, J. R. T. (2013). Akuntabilitas Pelayanan Publik dalam Pelaksanaan E-Procurement di Kota Pangkalpinang. JKAP (Jurnal Kebijakan Dan Administrasi Publik), 17(1), 15-28.

Ardiansyah, M. K. I., Yunizar, Y., \& Harsanto, B. (2016). Shariah-Compliant E-Commerce Models and Consumer Trust. Al-Iqtishad: Journal of Islamic Economics, 8(2), 243-254. https://doi. org/10.15408/aiq.v8i2.2913

Asosiasi Penyelenggara Jasa Internet Indonesia (APJII). (2016). Laporan Survey Penetrasi Internet Indonesia. Jakarta, Indonesia: Asosiasi Penyelenggara Jasa Internet Indonesia (APJII).

Astuti, N. C., \& Nasution, R. A. (2014). Technology readiness and E-commerce adoption among entrepreneurs of SMEs in Bandung city, Indonesia. Gadjah Mada International Journal of Business, 16(1), 69-88.

Bawden, D., \& Robinson, L. (2009). The dark side of information: overload, anxiety and other paradoxes and pathologies. Journal of Information Science, 35(2), 180-191. https://doi. org/10.1177/0165551508095781

Bayat, A. (2005). Islamism and Social Movement Theory. Third World Quarterly, 26(6), 891-908. https://doi. org/10.1080/01436590500089240

Blom-Hansen, J. (1997). A 'new institutional' perspective on policy networks. Public Administration, 75, 669-693.

Buechler, S. M. (1993). Beyond Resource Mobilization? Emerging Trends in Social Movement Theory. The Sociological Quarterly, 34(2), 217-235. https://doi.org/10.1111/j.1533-8525.1993. tboo388.x 
Bulger, M. E., Mayer, R. E., \& Metzger, M. J. (2014). Knowledge and processes that predict proficiency in digital literacy. Reading and Writing, 27(9), 1567-1583. https://doi.org/10.1007/s11145-0149507-2

Clark, R. (2016). "Hope in a hashtag": the discursive activism of \#WhylStayed. Feminist Media Studies, 16(5), 788-804. https://doi.org/10.1080/14680777.2016. 1138235

Coleman, A. (2014). Migration from resource based to knowledge based strategy for e-health implementation in developing countries. Journal of Communication [Delhi], 5(1), 1-7. https://doi.org/10.108 o/o976691X.2014.11884819

Cope, B., \& Kalantzis, M. (2009). "Multiliteracies": New Literacies, New Learning. Pedagogies: An International Journal, 4(3), 164-195. https://doi. org/10.1080/15544800903076044

Crouch, C. (2001). Industrial Society/Postindustrial Society: History of the Concept. In N. J. Smelser \& P. Baltes (Eds.), International Encyclopedia of the Social \& Behavioral Sciences (73477351). Oxford: Elsevier. https://doi. org/10.1016/Bo-08-043076-7/00126-1

Dowding, K. (1995). Model or Metaphor? A Critical Review of the Policy Network Approach. Political Studies, 43(1), 136-158. https://doi. org/10.1111/j.1467-9248.1995.tbo1705.X

Drori, G. S. (2014). The Internet as a Global Social Problem. Handbook of Social Problems: A Comparative International Perspective. https://doi. org/10.4135/9781412973526.n25

Elo, S., Kääriäinen, M., Kanste, O., Pölkki, T., Utriainen, K., \& Kyngäs, H. (2014). Qualitative Content Analysis. SAGE Open, 4(1), 215824401452263. https:// doi.org/10.1177/2158244014522633

Emejulu, A., \& McGregor, C. (2016). Towards a radical digital citizenship in digital education. Critical Studies in Education.
Paterson's Land, Moray House School of Education, University of Edinburgh, UK: Routledge. https://doi.org/10.1080 /17508487.2016.1234494

Erstad, O. (2010). Conceptions of Technology Literacy and Fluency. In P. Peterson, E. Baker, \& B. McGaw (Eds.), International Encyclopedia of Education (3441). Oxford: Elsevier. https://doi. org/10.1016/B978-o-o8-0448947.00694-1

Gamire, E., \& Pearson, G. (2006). Tech tally: approaches to assessing technological literacy. (E. Gamire \& G. Pearson, Eds.), Literacy. Washington D.C., USA: The National Academics Press.

Godwin, P. (2006). Information Literacy in the Age of Amateurs. Innovation in Teaching and Learning in Information and Computer Sciences, 5(4), 268-287. https://doi.org/10.11120/ ital.2006.05040268

Gruszczynska, A., \& Pountney, R. (2013). Developing the Concept of Digital Literacy in the Context of Schools and Teacher Education. Enhancing Learning in the Social Sciences, 5(1), 25-36. https://doi.org/10.1112o/ elss.2013.05010025

Harjito, Y., Achyani, F., \& Payamta. (2015). Implementasi E-Procurement Ditinjau Dari Kesuksesan Sistem Teknologi Informasi Dengan Menggunakan Model DeLone Dan McLean. Jurnal Ekonomi Dan Bisnis, XVIII(1), 61-82.

Helsper, E. J., \& Eynon, R. (2013). Distinct skill pathways to digital engagement. European Journal of Communication, 28(6), 696-713. https://doi. org/10.1177/0267323113499113

Hidayat, A. N. (2017). E-Learning Implementation in Islamic Education Innovation. HUNAFA: Jurnal Studia Islamika, 14(1), 17-36. https://doi. org/10.24239/jsi.v14i1.46o.17-36

Hilbert, M. (2009). The maturing concept of E-democracy: From E-voting and 
online consultations to democratic value out of jumbled online chatter. Journal of Information Technology and Politics, 6(2), 87-110. https://doi. org/10.108o/19331680802715242

Huang, V. G. (2016). Speaking out: Testimonial narratives of Chinese cyberpetitioners under networked authoritarianism. Discourse, Context and Media, 14, 18-27. https://doi. org/10.1016/j.dcm.2016.09.002

Ilomäki, L., Paavola, S., Lakkala, M., \& Kantosalo, A. (2016). Digital competence - an emergent boundary concept for policy and educational research. Education and Information Technologies, 21(3), 655-679. https:// doi.org/10.1007/s10639-014-9346-4

Jordana, T. A., \& Suwarto, D. H. (2017). Pemetaan Program Literasi Digital di Universitas Negeri Yogyakarta. INFORMASI: Kajian Ilmu Komunikasi, 47(2), 167-180.

Kahani, M. (2006). Experiences in e-Voting. Journal of E-Government, 2(3), 113-125. https://doi.org/10.1300/J399vo2no3_o6

Kalman, J. (2008). Beyond defenition: central concepts for understanding literacy. International Review of Education, 54 (56), 523-538. https://doi.org/10.1007/ s11159-008-9104-1

Kapucu, N., \& Demiroz, F. (2011). Measuring Performance for Collaborative Public Management Using Network Analysis Methods and Tools. Public Performance $\mathcal{E}$ Management Review, 34(4), 549-579. https://doi.org/10.2753/PMR15309576340406

Kellner, D. (2001). New Technologies/New Literacies: Reconstructing Education for the New Millennium. International Journal of Technology and Design Education, 11(1), 67-81. https://doi. org/10.1023/A:1011270402858

Knox, J. (2014). Digital culture clash: "massive" education in the E-learning and Digital Cultures MOOC. Distance
Education, 35(2), 164-177. https://doi. org/10.1080/01587919.2014.917704

Koltay, T. (2011). The media and the literacies: media literacy, information literacy, digital literacy. Media, Culture $\mathcal{E}$ Society , 33(2), 211-221. https://doi. org/10.1177/0163443710393382

Krohn, W. (2001). Knowledge Societies. In N. J. Smelser \& P. Baltes (Eds.), International Encyclopedia of the Social \& Behavioral Sciences (8139-8143). Oxford: Elsevier. https://doi.org/10.1016/Bo-o8-0430767/03190-9

Kurnia, N., \& Astuti, S. I. (2017). Peta Gerakan Literasi Digital di Indonesia: Studi tentang Pelaku, Ragam Kegaitan, Kelompok Sasaran dan Mitra. Informasi: Kajian Ilmu Komunikasi, 47(2), 149-166.

Martin, A., \& Grudziecki, J. (2006). DigEuLit: Concepts and Tools for Digital Literacy Development. Innovation in Teaching and Learning in Information and Computer Sciences, 5(4), 249-267. https://doi.org/10.1112o/ ital.2006.05040249

McBeth, M., Jones, M., \& Shanahan, E. (2014). The Narrative Policy Framework. In P. A. Sabatier \& C. M. Weible (Eds.), Theories of the Policy Process (Third, 225-266). Philadelphia, USA: Westvew Press.

McNall, S. G. (1986). Class Analysis and Social Movement Theory: Toward A Synthesis. Mid-American Review of Sociology, 11(2), 3-28.

Morgan, D. L. (1993). Qualitative Content Analysis: A Guide to Paths not Taken. Qualitative Health Research, 3(1), 112-121. https://doi. org/10.1177/104973239300300107

Mueller, C. M., \& Judd, C. M. (1981). Belief Constraint and Belief Consensus: Toward an Analysis of Social Movement Ideologies - A Research Note. Social Forces, 6o(1), 182-187.

Nielsen, K. B. (2009). Four narratives of 
a social movement in West Bengal. South Asia: Journal of South Asia Studies, 32(3), 448-468. https://doi. org/10.1080/o0856400903374335

Olson, M. (1971). The logic of collective action: public goods and the theory of groups. London, U.K: Harvard University Press.

Pinto, M., Pulgarín, A., \& Escalona, M. I. (2014). Viewing information literacy concepts: a comparison of two branches of knowledge. Scientometrics, 98(3), 2311-2329. https://doi.org/10.1007/ s11192-013-1166-6

Refle, J.-E. (2016). What is a Social Movement? Social Movement Studies, 15(2), 244245. https://doi.org/10.1080/14742837.2 015.1027765

Reynolds, R. (2016). Defining, designing for, and measuring "social constructivist digital literacy" development in learners: a proposed framework. Educational Technology Research and Development, 64(4), 735-762. https:// doi.org/10.1007/s11423-015-9423-4

Robinson, L., Cotten, S. R., Ono, H., QuanHaase, A., Mesch, G., Chen, W., ... Stern, M. J. (2015). Digital inequalities and why they matter. Information, Communication E Society, 18(5), 569582. https://doi.org/10.1080/136911 8X.2015.1012532

Santosa, S. (2001). The Application of E-Commerce in Shipping Warehousing Industri. Jurnal Akuntansi $\mathcal{E}$ Keuangan, 3(2), 126-141.

Scott, J. (1988). Social Network Analysis. Sociology, 22(1), 109-127. https://doi. org/10.1177/0038038588022001007

Sterling,C.(2009).Encyclopedia ofJournalism. Encyclopedia of Journalism. 2455 Teller Road, Thousand Oaks California 91320 United States: SAGE Publications, Inc. https://doi.org/10.4135/9781412972048

Stokes, W. (2008, December). Literacy. In N. J. Salkind \& K. Rasmussen (Eds.), Encyclopedia of Educational Psychology (Vol. 2, 6o8-616). Thousand Oaks, CA:
SAGE Publications.

Travaglino, G. A. (2014). Social sciences and social movements: The theoretical context. Contemporary Social Science, 9(1), 1-14. https://doi.org/10.108o/21582 041.2013 .851406

Wasserman, S., \& Faust, K. (1994). Social Network Analysis: Methods and Application. Cambridge, UK: Cambridge University Press.

Webster, F. (2010). The Information Society Revisited. In L. A. Lievrouw \& S. Livingstone (Eds.), Handbook of New Media: Social Shaping and Social Consequences of ICTs (307-327). London: SAGE Publication Ltd. https:// doi.org/10.4135/9781446211304

Wentink, M. M., Prieto, E., de Kloet, A. J., Vliet Vlieland, T. P. M., \& Meesters, J. J. L. (2017). The patient perspective on the use of information and communication technologies and e-health in rehabilitation. Disability and Rehabilitation: Assistive Technology, o(o), 1-6. https://doi.org/10.108o/17483 107.2017.1358302 